\title{
Pemodelan Pemilihan Moda Rute Medan-Binjai Antara Kereta Api dan Bus dengan Metode Stated Preference
}

\author{
Indra Markeshwan ZAGOTO ${ }^{1}$ Charles SITINDAON ${ }^{2} \cdot$ Oloan SITOHANG $^{3}$
}

\begin{abstract}
The objective of this research is to construct a user mode choice model between BRT Mebidang and Sri Lelawangsa railway line, and further to test the sensitivity of trip user choice toward certain change in attributes value. Data were collected using stated preference survey, and analysed using logit biner model. Based on user responses, it was found that $50.96 \%$ trip purpose is related to family/social matter, while the main reason to travel using both modes is convenience. The utility function of Mebidang bus is given as follow: $U_{B M^{-} K A}=7.256-0.565 X_{1}-0.031 X_{2}+0.101 X_{3}-$ $0.071 X_{4}+0.088 X_{5}$ where $X_{1}$ is cost, $X_{2}$ is time, $X_{3}$ is headway, $X_{4}$ is accesstime, dan $X_{5}$ is service quality. The model shows that cost, time, and access time negatively affect Mebidang bus utility thus will lower the probability of user choosing bus over rail. In terms of sensitivity, access time and service quality are considered more sensitive in affecting the probability of choosing bus.
\end{abstract}

Kata kunci: stated-preference, pemilihan moda, bus, kereta, medan, binjai

\section{Pendahuluan}

Pertumbuhan wilayah di daerah perkotaan seperti kota Medan lebih cepat dibandingkan pertumbuhan wilayah di daerah pedalaman. Hal ini disebabkan oleh kota Medan banyak menawarkan berbagai macam sarana dan lapangan pekerjaan. Semua hal ini menyebabkan semakin meningkatnya mobilitas (pergerakan) dari Binjai ke Medan begitupun sebaliknya. Pergerakan ini tentunya membutuhkan sarana transportasi untuk memindahkan orang maupun barang.

Dalam melakukan perjalanan Medan-Binjai atau sebaliknya pelaku perjalanan dihadapkan pada pilihan jenis moda transportasi massal yang akan melayani penumpang Medan dan Binjai, yaitu transportasi jalan Bus Trans Mebidang dan Transportasi Rel yaitu Kerata Api Sri Lelawangsa. Hal ini dikarenakan dengan menggunakan sistem angkutan umum massal inilah masalah kemacetan kota diharapkan bisa diatasi.

Adanya kompetisi dalam pemilihan kedua moda yaitu antara Kereta Api Sri Lelawangsa dan Bus Mebidang oleh pelaku perjalanan sangat terkait oleh kondisi sosioekonomi pelaku perjalanan dan juga karakteristik dan segala atribut yang ada pada moda yang bersangkutan. Pemilihan moda dapat juga dikatakan sebagai tahap terpenting dalam perencanaan transportasi. Ini karena peran kunci angkutan umum dalam berbagai kebijakan transportasi. Tidak seorangpun dapat menyangkal bahwa moda transportasi angkutan umum menggunakan ruang jalan jauh lebih efisien daripada moda transportasi angkutan pribadi. Hal ini

\footnotetext{
${ }^{1}$ Program Studi Teknik Sipil Universitas Katolik Santo Thomas e-mail: markeshwan@yahoo.co.id

${ }^{2}$ Staf Pengajar Teknik Sipil Universitas Katolik Santo Thomas e-mail: charles_sitindaon@yahoo.co.id

${ }^{3}$ Staf Pengajar Teknik Sipil Universitas Katolik Santo Thomas e-mail: obed_sito@yahoo.com
} 
menyangkut efisiensi pergerakan didaerah perkotaan, ruang yang disediakan kota untuk dijadikan prasarana transportasi, dan banyaknya pilihan moda transportasi yang dapat dipilih penduduk.

\section{Tujuan}

Kegiatan studi dimaksudkan untuk mengidentifikasi karakteristik pengguna moda Kereta Api Sri Lelawangsa dan Bus Mebidang, mengidentifikasi faktor-faktor yang mempengaruhi pemilihan moda oleh pelaku perjalanan, menyusun bentuk model yang dapat menjelaskan probabilitas pemilihan moda, serta mengidentifikasi sensitifitas model dari respons individu pelaku perjalanan apabila dilakukan perubahan terhadap salah satu atribut perjalanan yang mendukung utilitas pemilihan moda.

\section{Tinjauan Pustaka}

\section{Model Pemilihan Diskret}

Akiva dan Lerman (1985) menyatakan dalam analisis pilihan konsumen, model pemilihan didasarkan kepada keinginan konsumen dalam memaksimalkan kepuasannya (utilitas) dalam mengkonsumsi pelayanan salah satu pilihan moda. Prosedur model ini diawali dengan menentukan nilai-nilai parameter dari sebuah fungsi kepuasan yang dipengaruhi oleh beberapa variabel bebas. Model ini disebut sebagai model pilihan biner (binary choice model). Sebuah contoh umum fungsi kepuasan dapat dilihat seperti

dimana,

$$
V_{\text {in }}=f\left(X_{\text {in }}\right) \quad \text { atau } \quad V_{\text {jn }}=f\left(X_{\text {jn }}\right) \text {. }
$$

$\mathrm{V}_{\text {in }}$ dan $\mathrm{V}_{\text {jn }}$ : nilai kepuasan konsumen yang mencerminkan perilaku konsumen (consumer behavior).

$\mathrm{X}_{\mathrm{in}}$ dan $\mathrm{X}_{\mathrm{jn}}$ : variabel yang berpengaruh terhadap perilakunya untuk memaksimalkan kepuasannya.

f : fungsi matematis.

Sehingga persamaan regresi fungsi kepuasan dimaksud dapat kita bentuk menjadi:

dimana,

$$
\mathrm{V}_{\mathrm{in}} / \mathrm{U}=\beta_{1} \mathrm{X}_{\mathrm{in} 1}+\beta_{2} \mathrm{X}_{\mathrm{in} 2}+\ldots+\beta_{\mathrm{k}} \mathrm{X}_{\mathrm{ink}}
$$

$\mathrm{V}_{\text {in }} / \mathrm{U} \quad$ : nilai kepuasan konsumen memakai moda i (maksimum kepuasan).

$\mathrm{X}_{\text {in1 }} \mathrm{s} / \mathrm{d} \mathrm{X}_{\text {ink }}$ : $\quad$ sekelompok variabel bebas yang mempengaruhi kepuasan maksimum.

$\beta_{1} \mathrm{~s} / \mathrm{d} \beta_{\mathrm{k}} \quad: \quad$ koefisien regresi/parameter variabel bebas.

\section{Utilitas Acak}

Pembangunan model diasumsikan bahwa utilitas (U) dapat dinyatakan dalam 2 komponen, yaitu: $V_{\text {in }}$ yang terukur sebagai fungsi dari atribut terukur (deterministik), dan bagian acak $\epsilon_{\text {in }}$ yang mencerminkan hal tertentu dari setiap individu termasuk kesalahan yang dilakukan oleh pemodelan.

dimana :

$$
\mathrm{U}_{\text {in }}=\mathrm{V}_{\text {in }}+\epsilon_{\text {in }}
$$

$\mathrm{U}_{\text {in }} \quad=$ Utilitas alternatif $\mathrm{i}$ bagi pembuat keputusan $\mathrm{n}$.

$\mathrm{V}_{\text {in }} \quad=$ Fungsi deterministik utilitas moda i bagi individu $\mathrm{n}$.

$\epsilon_{\text {in }} \quad=$ Kesalahan acak (random error) komponen statistik. 


\section{Model Logit Biner}

Model logit binomial dibangun atas dasar asumsi $\varepsilon_{\mathrm{n}}=\varepsilon_{\mathrm{jn}}-\varepsilon_{\mathrm{in}}$ akan bersifat bebas dan tersebar secara identik (IID) menurut fungsi sebaran Gumbel seperti pada persamaan di bawah ini

$$
\mathrm{F}\left(\varepsilon_{\mathrm{n}}\right)=\frac{1}{\left(1+\mathrm{c}^{\left.-\mu \varepsilon_{\mathrm{n}}\right)}\right.} ; \quad \mu>0 ;-\infty<\varepsilon_{\mathrm{n}}<\infty
$$

Pada kasus dua alternatif moda, peluang terpilihnya moda i dapat didekati dengan persamaan (2.14) berikut.

$$
P_{n}(i)=\frac{\exp \left(\beta\left(v_{i n}\right)\right\}}{\left|\exp \left\{\beta\left(v_{j n}\right)\right\} \exp \left\{\beta\left(v_{j n}\right)\right\}\right|}
$$

Dengan mengasumsikan $V_{\text {in }}$ dan $V_{\text {jn }}$ linear dalam parameternya, maka persamaan (2.14) dapat ditulis kembali dalam persamaan (2.15) berikut.

$$
\begin{aligned}
& \mathrm{P}_{\mathrm{j}}=\frac{\exp ^{\mathrm{U}_{j}}}{\exp ^{U_{j}}+\exp ^{U_{i}}}=\frac{\exp ^{\left(\mathrm{U}_{j-\mathrm{j}}\right)}}{1 \exp ^{\left(\mathrm{U}_{j-j} j\right.}} \\
& \mathrm{P}_{\mathrm{i}}=1-\mathrm{P}_{\mathrm{j}}=\frac{1}{1 \operatorname{lexp}^{\left(\mathrm{U}_{j-1} j\right.}}
\end{aligned}
$$

dimana :

$\mathrm{P}_{\mathrm{j}} \quad=$ Probabilitas $(\%)$ peluang moda $\mathrm{j}$ untuk dipilih

$\mathrm{P}_{\mathrm{i}} \quad=$ Probabilitas (\%) peluang moda I untuk dipilih

$\mathrm{U}_{\mathrm{j}} \quad=$ Nilai parameter atau nilai kepuasan menggunakan moda $\mathrm{j}$.

$\mathrm{U}_{\mathrm{i}} \quad=$ Nilai parameter atau nilai kepuasan menggunakan moda $\mathrm{i}$.

\section{Metodologi Penelitian}

Untuk memperoleh data yang diperlukan dalam penelitian ini maka dilakukan survei terhadap masing-masing penumpang, baik penumpang Kereta Api Sri Lelawangsa maupun penumpang Bus Trans Mebidang tujuan Medan - Binjai. Survei yang dilakukan berupa memberikan angket kuisioner serta wawancara langsung kepada penumpang yang sedang menunggu keberangkatan Kereta Api maupun Bus Mebidang.

Data primer ini diperoleh dari hasil pembagian kuisioner pada survei penelitian di lapangan. Data ini dapat dikumpulkan melalui dua tahap berikut :

1. Membagikan kuisioner kepada pengguna jasa angkutan penumpang, dalam hal ini Kereta Api Sri Lelawangsa maupun Bus Trans Mebidang.

2. Pelaksanaan survei dengan melakukan teknik wawancara langsung terhadap penumpang yang dilakukan oleh surveyor. Data yang diperoleh dengan teknik wawancara ini digunakan untuk memperkuat informasi yang diperoleh melalui kuisioner dan memformulasikan permasalahan yang dihadapi.

Adapun bentuk pertanyaan form survei direncanakan untuk:

1. Mengetahui kondisi eksisting dan karakteristik umum pengguna jasa angkutan, yaitu berupa kondisi sosioekonomi dan informasi dasar melakukan perjalanan dengan menggunakan kedua moda tersebut.

2. Untuk mengetahui preferensi responden seandainya beberapa atribut pelayanan yang ditawarkan mengalami perubahan (baik itu peningkatan, pengurangan ataupun sama sekali tidak ada perubahan) pada biaya/tarif perjalanan, waktu tempuh, jedah 
keberangkatan (headway) di dalam angkutan yang dilakukan berdasarkan kondisi eksisting pada setiap moda.

Ada beberapa preferensi yang ditawarkan kepada responden, dimana masing masing atribut yang ditawarkan mengalami perubahan. Perubahan yang diberikan dapat berupa peningkatan ataupun penurunan nilai dari masing-masing atribut pelayanan. Berikut atribut pelayanan dari masing-masing moda yang ditawarkan kepada responden:
a. Atribut biaya perjalanan. Notasi parameter atribut : cost.
b. Atribut waktu tempuh perjalanan. Notasi parameter atribut : time.
c. Atribut jadwal keberangkatan. Notasi parameter atribut : headway.
d. Atribut waktu untuk mencapai stasiun keberangkatan.
Notasi parameter atribut: access time.
e. Atribut pelayanan. Notasi parameter atribut : service.

\section{Hasil dan Pembahasan}

\section{Karakteristik Responden}

Secara umum berdasarkan tingkat pendapatan perbulan responden terlihat bahwa pengguna Kereta Api Sri Lelawangsa paling banyak adalah responden dengan tingkat pendapatan $<\mathrm{Rp}$. 1.500.000,- (30,93\%). Untuk pengguna Bus Trans Mebidang paling banyak adalah responden dengan tingkat pendapatan Rp. 1500.000 - 2.499.999- dan Rp. 2.500 .000 - 3.499.999,$(32,69 \%)$.

Tabel 1 Distribusi Tingkat Pendapatan Responden Pengguna KA Sri Lelawangsa dan Bus Trans Mebidang untuk Perjalanan Medan - Binjai

\begin{tabular}{|c|r|c|c|c|c|}
\hline \multirow{2}{*}{ No } & \multirow{2}{*}{$\begin{array}{c}\text { Pendapatan responden per } \\
\text { bulan }\end{array}$} & \multicolumn{4}{|c|}{ Penggunaan Moda } \\
\cline { 3 - 6 } & & \multicolumn{2}{|c|}{ Kereta Api } & \multicolumn{2}{c|}{ Bus Mebidang } \\
\cline { 3 - 6 } & & Jumlah & $\%$ & Jumlah & $\%$ \\
\hline 1 & $<$ Rp. 1500.000,- & 30 & 30.93 & 17 & 16.35 \\
\hline 2 & Rp. 1500.000-2.499.999- & 28 & 28.87 & 34 & 32.69 \\
\hline 3 & Rp. 2.500.000-3.499.999,- & 20 & 20.62 & 34 & 32.69 \\
\hline 4 & Rp.3500.000-4.499.999,- & 14 & 14.43 & 11 & 10.58 \\
\hline 5 & Rp.4500.000-6.000.000,- & 3 & 3.09 & 5 & 4.81 \\
\hline 6 & $>$ Rp.6.000.000,- & 2 & 2.06 & 3 & 2.88 \\
\hline \multicolumn{7}{r}{ Jumlah } & 97 & 100 & 104 & 100 \\
\hline
\end{tabular}

Berdasarkan hasil survei yang dilakukan dengan tujuan perjalanan terlihat bahwa karektertistik pengguna Kereta Api Sri Lelawangsa paling banyak melakukan perjalanan dengan tujuan urusan Bisnis/Bekerja sebesar 28,87\% responden. Untuk karektertistik pengguna Bus Trans Mebidang juga paling banyak melakukan perjalanan dengan tujuan urusan Keluarga/Sosial sebesar 50,96\% responden.

Tabel 2 Distribusi Tujuan Perjalanan Responden Pengguna KA Sri Lelawangsa dan Bus Trans Mebidang untuk Perjalanan Medan - Binjai

\begin{tabular}{|l|l|l|l|l|l|}
\hline \multirow{2}{*}{ No } & \multirow{2}{*}{ Tujuan Perjalanan } & \multicolumn{4}{|c|}{ Penggunaan Moda } \\
\cline { 3 - 6 } & & Kereta Api & \multicolumn{2}{|l|}{ Bus Mebidang } \\
\cline { 3 - 6 } & & Jumlah & $\%$ & Jumlah & $\%$ \\
\hline 1 & Bisnis/Bekerja & 28 & 28.87 & 27 & 25.96 \\
\hline 2 & Berlibur/Rekreasi & 17 & 17.53 & 10 & 9.62 \\
\hline 3 & Pendidikan & 15 & 15.46 & 10 & 9.62 \\
\hline 4 & Urusan Keluarga/ Sosial & 25 & 25.77 & 53 & 50.96 \\
\hline
\end{tabular}




\begin{tabular}{|c|c|c|c|c|c|}
\hline \multirow{3}{*}{ No } & \multirow{3}{*}{ Tujuan Perjalanan } & \multicolumn{4}{|c|}{ Penggunaan Moda } \\
\hline & & \multicolumn{2}{|c|}{ Kereta Api } & \multicolumn{2}{|c|}{ Bus Mebidang } \\
\hline & & Jumlah & $\%$ & Jumlah & $\%$ \\
\hline 5 & Berobat/ Check Up & 2 & 2.06 & 0 & 0.00 \\
\hline 6 & Lain-lain & 10 & 10.31 & 4 & 3.85 \\
\hline & Jumlah & 97 & 100 & 104 & 100 \\
\hline
\end{tabular}

Tabel 3 Distribusi Alasan Pemilihan Moda Responden Pengguna KA Sri Lelawangsa dan Bus Trans Mebidang untuk Perjalanan Medan - Binjai

\begin{tabular}{|l|l|l|l|l|l|}
\hline \multirow{2}{*}{ No } & \multirow{2}{*}{ Alasan Pemilihan Moda } & \multicolumn{4}{l|}{ Penggunaan Moda } \\
\cline { 3 - 6 } & & \multicolumn{2}{l|}{ Kereta Api } & \multicolumn{2}{l|}{ Bus Mebidang } \\
\cline { 3 - 6 } & & Jumlah & $\%$ & Jumlah & $\%$ \\
\hline 1 & Pertimbangan Kecepatan/waktu & 66 & 68.04 & 19 & 18.27 \\
\hline 2 & Pertimbangan keselamatan/keamanan & 8 & 8.25 & 12 & 11.54 \\
\hline 3 & Pertimbangan kenyamanan & 8 & 8.25 & 19 & 18.27 \\
\hline 4 & Pertimbangan kemudahan & 7 & 7.22 & 51 & 49.04 \\
\hline 5 & Pertimbangan harga (murah) & 8 & 8.25 & 3 & 2.88 \\
\hline \multicolumn{2}{|l|}{ Jumlah } & 97 & 100 & 104 & 100 \\
\hline
\end{tabular}

Dilihat dari alasan pemilihan moda, pengguna Kereta Api Sri Lelawangsa paling banyak memilih Kereta Api Sri lelawangsa karena pertimbangan kecepatan/waktu (68,04\%). Sementara untuk pengguna Bus Trans Mebidang paling banyak memilih Bus Trans Mebidang karena pertimbangan kemudahan (49,04\%).

\section{Fungsi Utilitas}

Dari beberapa fungsi persamaan utilitas selisih yang dihasilkan, maka dipilih fungsi utilitas selisih yang terbaik diantaranya adalah:

1. Persamaan dengan konstanta terkecil pada persamaan $5(\mathrm{a} 0=0,665)$

$\mathrm{UBM}-\mathrm{KA}=0.665+0.074 \mathrm{X} 5$

2. Persamaan dengan F-stat terbesar pada persamaan $5(\mathrm{~F}=843.083)$

$\mathrm{UBM}-\mathrm{KA}=0.665+0.074 \times 5$

3. Persamaan dengan $\mathrm{R} 2$ terbesar pada persamaan $31(\mathrm{R} 2=0.338)$

$\mathrm{UBM}-\mathrm{KA}=7.256-0.565 \mathrm{X} 1-0.031 \mathrm{X} 2+0.101 \mathrm{X} 3-0.071 \mathrm{X} 4+0.088 \mathrm{X} 5$

Dengan mempertimbangkan ketiga parameter tersebut maka dipilih satu persamaan utilitas fungsi binomial logit terbaik yaitu persamaan 31, dengan nilai R2 terbesar, selain memiliki nilai R2 terbesar persamaan tersebut juga memiliki nilai F-stat yang besar yaitu sebesar 511.998. Persamaan itu adalah:

$$
\mathrm{U}_{\mathrm{BM}-\mathrm{KA}}=7.256-0.565 \mathrm{X}_{1}-0.031 \mathrm{X}_{2}+0.101 \mathrm{X}_{3}-0.071 \mathrm{X}_{4}+0.088 \mathrm{X}_{5}
$$

$\mathrm{X}_{1}=$ selisih atribut Cost,

$\mathrm{X}_{2}=$ selisih atribut time,

$\mathrm{X}_{3}=$ selisih atribut Headway,

$\mathrm{X}_{4}=$ selisih atribut access time,

$\mathrm{X}_{5}=$ selisih atribut service.

Selanjutnya menggunakan persamaan utilitas di atas, dihitung probabilitas pemilihan masingmasing moda sebagai berikut. 
Probabilitas pemilihan Bus Mebidang $\quad: \mathrm{P}_{\mathrm{BM}}=\frac{\exp \left(\mathrm{U}_{\mathrm{BM}-\mathrm{KA}}\right)}{1+\exp \left(\mathrm{U}_{\mathrm{BM}-\mathrm{KA}}\right)}$

Probabilitas pemilihan Kereta Api $\quad: \mathrm{P}_{\mathrm{KA}}=1-\mathrm{P}_{\mathrm{BM}}$

Bila selisih nilai utilitas antara KA Sri Lelawangsa dan Bus Trans Mebidang meningkat, maka probabilitas terpilihnya KA Sri Lelawangsa akan semakin meningkat. Sebaliknya bila selisih nilai utilitas antara KA Sri Lelawangsa dan Bus Trans Mebidang menurun, maka probabilitas terpilihnya KA Sri Lelawangsa akan semakin menurun.

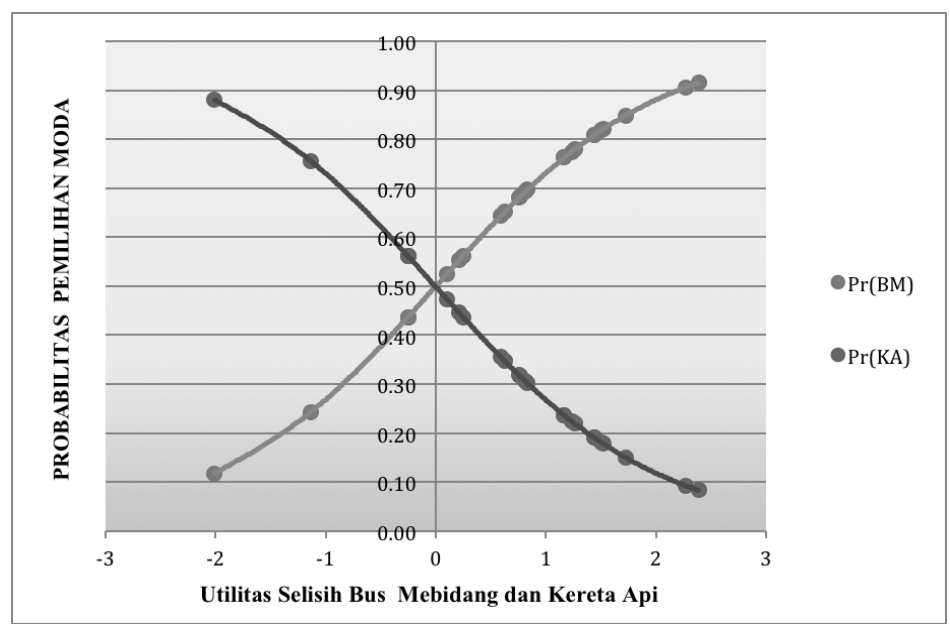

Gambar 1 Grafik Pemilihan Moda dengan Model Logit Biner

Dari grafik diatas dapat disimpulkan bahwa ketika nilai utilitas sama dengan satu (1) maka probabilitas pemilihan moda Bus Trans Mebidang akan semakin meningkat dan probabilitas pemilihan moda Kereta Api akan menurun. Artinya semakin besar nilai utilitas antara Bus Trans Mebidang dan KA Sri Lelawangsa maka probabilitas terpilihnya moda Bus Trans Mebidang akan semakin meningkat. Misalnya kita bisa lihat dari sisi utilitas atribut Cost (biaya), jika biaya/tarif Bus Trans Mebidang diturunkan sebesar Rp. 1.500,- atau menjadi Rp. 4.500 dari tarif normal Rp. 6.000,- maka utilitas antara Bus dan Kereta Api meningkat dan probabilitas terpilihnya moda Bus Trans Mebidang akan meningkat juga seperti yang tergambar pada grafik model Logit Biner diatas.

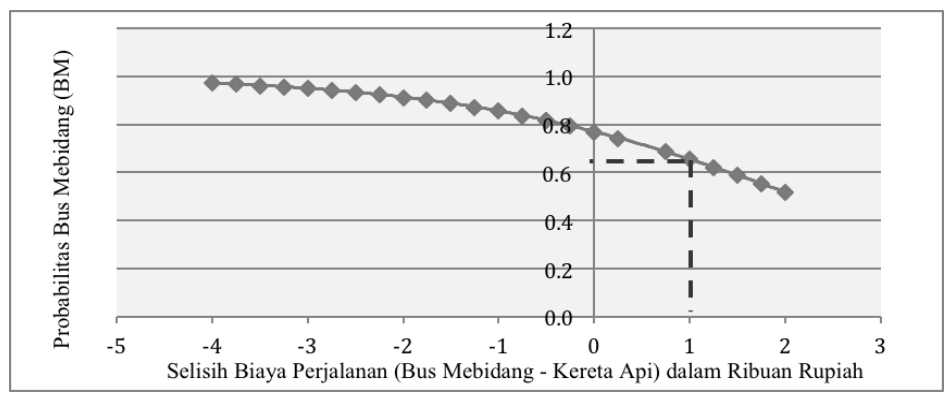

Gambar 2 Sensitifitas Model Logit Biner terhadap Biaya Perjalanan

Gambar di atas memperlihatkan arah kemiringan garis, menunjukkan arah kemiringan negatif, yaitu semakin besar perbedaan biaya (cost) akan semakin memperkecil probabilitas memilih Kereta Api Sri Lelawangsa. Bila biaya/tarif Bus Trans Mebidang dikurangkan 
sebesar Rp.1.000,- dan biaya/tarif Kereta Api tetap seperti tarif normal, maka probabilitas Bus Trans Mebidang akan meningkat.

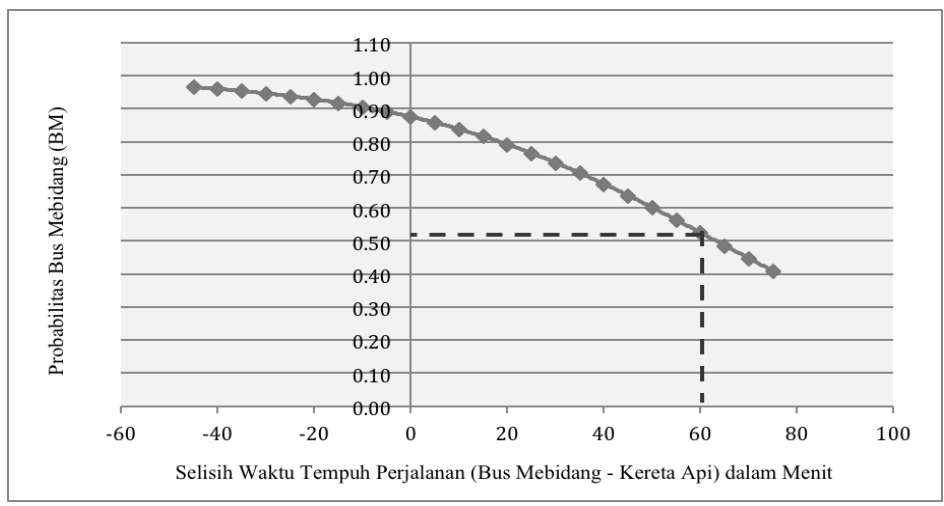

Gambar 3 Grafik Sensitifitas Model Logit Biner terhadap Waktu Tempuh Perjalanan

Dari grafik diatas dapat dilihat bahwa probabilitas memilih Bus Trans Mebidang akan lebih besar dan meningkat dari probabilitas memilih KA Sri Lelawangsa bila waktu tempuh perjalanan Bus Trans Mebidang dari Medan ke Binjai selama 60 menit, lebih cepat dari waktu tempuh awal yaitu selama 75 menit. Atau dapat juga kita simpulkan bahwa probabilitas memilih moda Bus Trans Mebidang akan meningkat apabila waktu tempuh perjalanan dari Medan ke Binjai lebih kecil dari 60 menit.

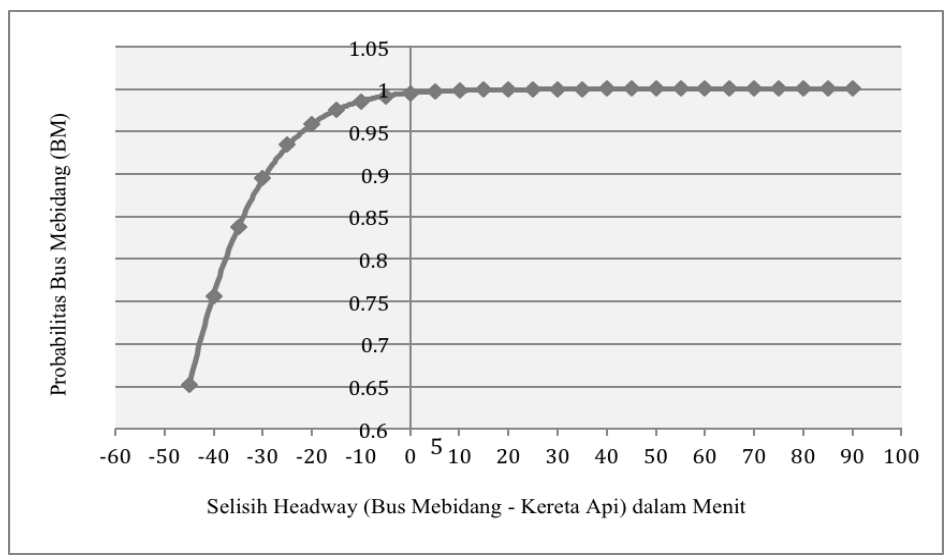

Gambar 4 Sensitifitas Model Logit Biner terhadap Headway

Dengan memperhatikan perubahan waktu untuk Headway, maka dapat disimpulkan bahwa probabilitas memilih Bus Trans Mebidang akan lebih besar dari probabilitas memilih Kereta Api bila headway (Jedah keberangkatan / waktu keberangkatan selanjutnya) selama 5 menit. Atau dapat juga disimpulkan bahwa jika waktu headway Bus Trans Mebidang hanya 5 menit dan headway Kereta Api 90 menit maka probabilitas memilih Bus Trans Mebidang akan meningkat.

Dari Gambar berikut dapat kita simpulkan bahwa, jika semakin besar lama waktu menuju halte keberangkatan Bus Trans Mebidang dibandingkan lama waktu menuju stasiun Kereta Api maka akan semakin memperkecil probabilitas pemilihan Bus Trans Mebidang. Dengan hanya memperhatikan perubahan lama waktu menuju stasiun keberangkatan, maka dapat disimpulkan bahwa probabilitas memilih Bus Trans Mebidang akan lebih besar dari probabilitas memilih KA Sri Lelawangsa bila lama waktu menuju halte selama 20 menit atau lebih kecil dari 20 menit. 


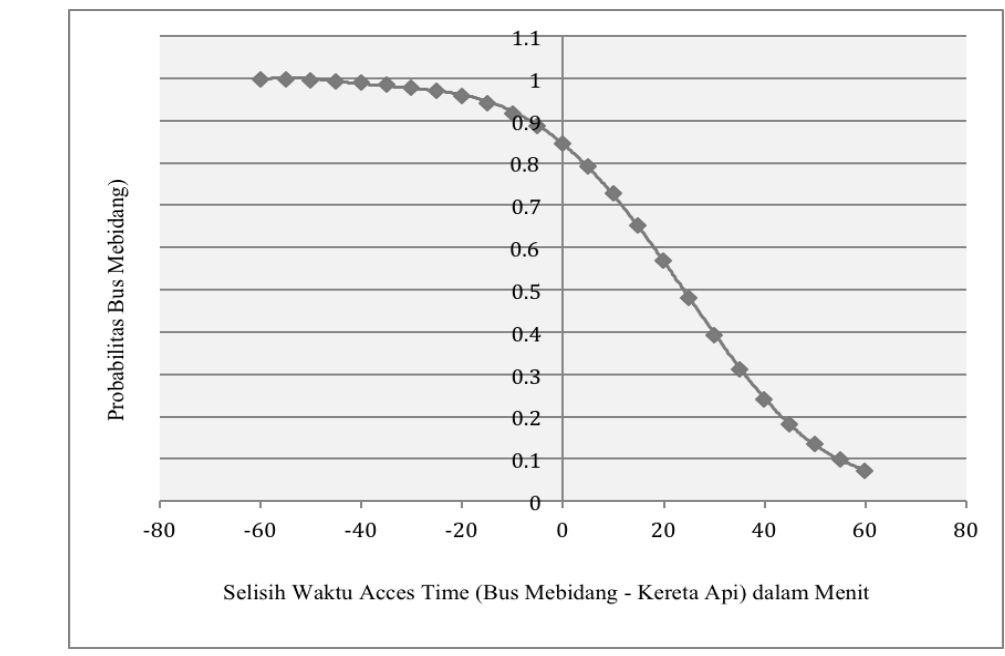

Gambar 5 Sensitifitas Model Logit Biner terhadap Waktu Tempuh Menuju Stasiun Keberangkatan (access time)

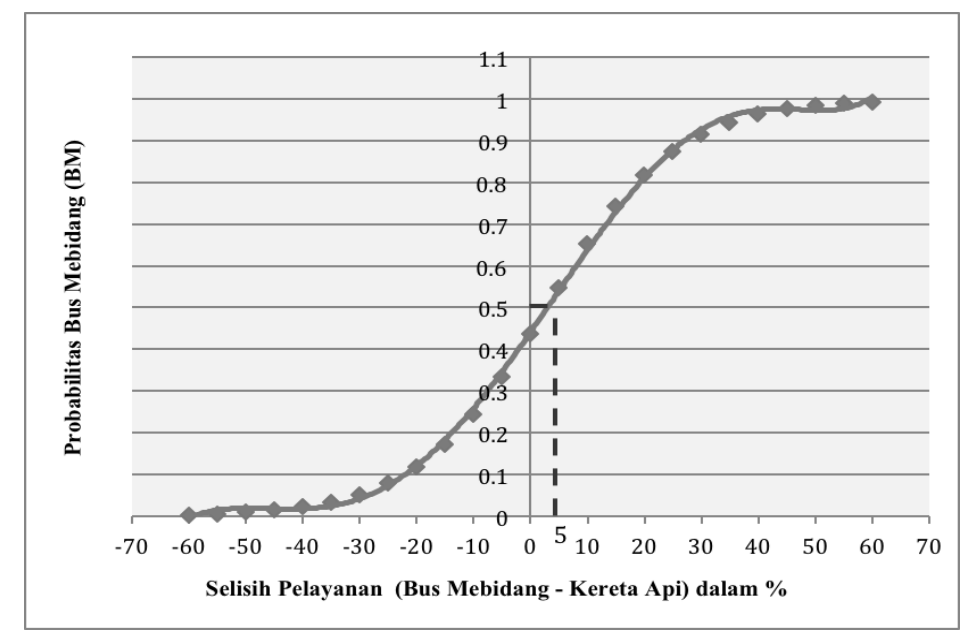

Gambar 6 Sensitifitas Model Logit Biner terhadap Pelayanan (service)

Dari grafik diatas dapat dilihat bahwa probabilitas memilih Bus Trans Mebidang akan lebih besar dan meningkat dari probabilitas memilih KA Sri Lelawangsa bila pelayanan Bus Trans Mebidang ditingkatkan sebesar 5\%. Atau dapat juga disimpulkan bahwa faktor pelayanan pada Bus Trans mebidang harus ditingkatkan agar probabilitas memilih Bus Trans Mebidang meningkat dibanding probabilitas memilih KA Sri Lelawangsa.

\section{Kesimpulan}

Model utilitas pemilihan moda Bus Trans Mebidang dan Kereta Api Sri Lelawangsa tujuan Medan - Binjai yang ditinjau dalam penelitian ini : $\mathrm{U}_{\mathrm{BM}-\mathrm{KA}}=7.256-0.565 \mathrm{X}_{1}$ $0.031 \mathrm{X}_{2}+0.101 \mathrm{X}_{3}-0.071 \mathrm{X}_{4}+0.088 \mathrm{X}_{5}$ yang mana, $\mathrm{X}_{1}=$ selisih atribut cost (rupiah); $\mathrm{X}_{2}=$ selisih atribut time dalam (menit); $\mathrm{X}_{3}=$ selisih atribut headway (menit); $\mathrm{X}_{4}=$ selisih atribut access (menit); $\mathrm{X}_{5}=$ selisih atribut service dalam satuan persen $(\%)$.

Hasil yang diperoleh dari analisa sensitifitas fungsi utilitas model logit biner dari lima atribut yang dianalisa hasilnya adalah sebagai berikut : Atribut cost, time, headway, dan access time ketika menuju stasiun keberangkatan memperlihatkan probabilitas pemilihan moda Bus Trans Mebidang meningkat apabila harga dan waktu setiap atribut diturunkan dan utilitas antara 
Bus dan Kereta Api besar. Sementara itu, atribut pelayanan (service) memperlihatkan probabilitas pemilihan moda Bus Trans Mebidang meningkat apabila pelayanan dan fasilitas Bus Trans Mebidang ditingkatkan.

\section{Referensi}

Ben-Akiva, M. dan Lerman, S.R. (1985). Discrete Choice Analysis: Theory and Application to Travel Demand, The MIT Press, Cambridge, Mass.

Black, J.A. (1981). Urban Transport Planning: Theory and Practice, London, Cromm Helm.

Bruton, M.J. (1985). Introduction to Transportation Planning, Hutchinson \& Co Ltd, London.

Gordon, Geoffrey. (1978). System Simulation, 2nd edition. Prentice Hall, Englewood Cliffs, New Jersey.

Kanafani, Adib. (1983). Transportation Demand Analysis. Mc Graw-Hill Book Company, New York.

Manheim, M.L. (1979). Fundamentals of Transportation System Analysis. Volume 1: Basic Concepts, The MIT Press.

Miro, Fidel. (2002). Perencanaan Transportasi, Erlangga, Jakarta.

Morlok, E. K. (1994). Pengantar Teknik dan Perencanaan Transportasi (terjemahan Johan K. Hainim), Penerbit Erlangga Jakarta.

Mukti, E.T. (2001). Kompetisi Pemilihan Moda Angkutan Penumpang Antar Kota Antara Kereta Api dan Bus, Tesis Magister Teknik Sipil, ITB.

Ortuzar, J. de D. dan Willumsen, L.G. (2001). Modelling Transport. John Wiley and Sons, West Sussex, England.

Panjaitan, I.M. (2012). Pemodelan Pemilihan Moda Angkutan Penumpang Karya Agung \& Koperasi Bintang Tapanuli dengan Ketepatan Model Probit dan Logit, Tugas Akhir Teknik Sipil USU.

Pearmain, D. dan Swanson J. (1991). Stated Preference Techniques, a Guide to Practice, 2nd Edition, Steel Davies Gleave and Hague Consulting Group.

Santoso, I. (1996) Perncanaan Prasarana Angkutan Umum, Pusat Studi Transportasi \& komunikasi Institut Teknologi Bandung (seri 002), Bandung. 